Table 1. The Clinical and Microbiological Characteristics of Patients With Influenza or COVID-19-Associated IPA During the 2019-2020 Season

\begin{tabular}{|c|c|c|}
\hline Characteristic & $\begin{array}{c}\text { Influenza } \\
\text { Patients }\end{array}$ & COVID-19 Patients \\
\hline Age, median y (range) & $73(66-79)$ & 75 (67-89) \\
\hline Sex, male & $4 / 5$ & $3 / 4$ \\
\hline Positive galactomannan ${ }^{a}$ & $5 / 5$ & $4 / 4$ \\
\hline Positive $\mathrm{PCR}^{\mathrm{a}}$ & $5 / 5$ & $2 / 4$ (2 tests ND) \\
\hline $\begin{array}{l}\text { Positive culture for Aspergillus } \\
\text { spp }^{a}\end{array}$ & $3 / 5$ & $4 / 4$ \\
\hline $\begin{array}{l}\text { Immunocompromised according } \\
\text { due to EORTC/MSG criteria }\end{array}$ & $2 / 5$ & $0 / 4$ \\
\hline Hematological malignancy & $1 / 5$ & $0 / 4$ \\
\hline Neutropenia & $2 / 5$ & $0 / 4$ \\
\hline COPD & $4 / 5$ & $0 / 4$ \\
\hline $\begin{array}{l}\text { Steroid use within } 28 \text { days } \\
\text { before admission }\end{array}$ & $2 / 5$ & $0 / 4$ \\
\hline $\mathrm{BMI}>30$ & $2 / 5$ & $2 / 4$ \\
\hline CKD stage III or higher & $1 / 5$ & $1 / 4$ \\
\hline ICU admission & $3 / 5$ & $4 / 4$ \\
\hline Mechanical ventilation & $3 / 5$ & $4 / 4$ \\
\hline Antifungal treatment & $\begin{array}{l}\text { Voriconazole and caspofungin }(n=1) \text {, voriconazole } \\
(n=3) \text {, death before treatment initiation }(n=1)\end{array}$ & $\begin{array}{l}\text { Voriconazole }(n=1) \text {, voriconazole followed by liposomal } \\
\text { amphotericin } B(n=2) \text {, death before treatment initiation }(n=1)\end{array}$ \\
\hline
\end{tabular}

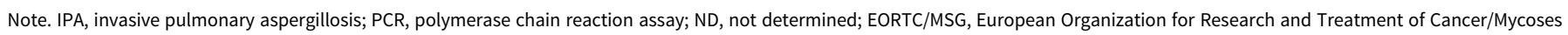
Study Group; COPD, chronic obstructive pulmonary disease; BMI, body mass index, CKD, chonic kidney disease, ICU, intensive care unit.

${ }^{a}$ These tests were performed on lower respiratory tract samples.

\section{References}

1. Rijnders BJA, Schauwvlieghe A, Wauters J. Influenza-associated pulmonary aspergillosis: a local or global lethal combination? Clin Infect Dis 2020. doi: org/10.1093/cid/ciaa010.

2. van Arkel ALE, Rijpstra TA, Belderbos HNA, van Wijngaarden P, Verweij PE, Bentvelsen RG. COVID-19-associated pulmonary aspergillosis. Am J Respir Crit Care Med 2020;202:132-135.

3. Rutsaert L, Steinfort N, Van Hunsel T, et al. COVID-19-associated invasive pulmonary aspergillosis. Ann Intensive Care 2020;10:71.
4. Bartoletti M, Pascale R, Cricca M, et al. Epidemiology of invasive pulmonary aspergillosis among COVID-19 intubated patients: a prospective study. Clin Infect Dis 2020. doi: org/10.1093/cid/ciaal065.

5. Alanio A, Delliere S, Fodil S, Bretagne S, Megarbane B. Prevalence of putative invasive pulmonary aspergillosis in critically ill patients with COVID-19. Lancet Respir Med 2020;8:e48-e49.

6. Van Biesen S, Kwa D, Bosman RJ, Juffermans NP. Detection of invasive pulmonary aspergillosis in COVID-19 with non-directed bronchoalveolar lavage. Am J Respir Crit Care Med 2020. doi: 10.1164/rccm.2020052018LE.

\title{
Aerosolized SARS-CoV-2 transmission risk: Surgical or N95 masks?
}

\author{
Petrick Periyasamy MMed ${ }^{1}$, B. H. Ng MMed ${ }^{1}$, Umi K. Ali MPath², Zetti Z. Rashid MPath² and Najma Kori MMed ${ }^{1}$ (1) \\ ${ }^{1}$ Department of Medicine, Universiti Kebangsaan Malaysia Medical Centre, Kuala Lumpur, Malaysia and ${ }^{2}$ Department of Medical Microbiology and Immunology, \\ Universiti Kebangsaan Malaysia Medical Centre, Kuala Lumpur, Malaysia
}

To the Editor-Based on available evidence, coronavirus disease 2019 (COVID-19) is thought to spread through close contact

Author for correspondence: Dr Najma Kori, Department of Medicine, Level 8, UKM Medical Centre, Jalan Haji Yaakob Latif, Cheras, 56000, Kuala Lumpur. E-mail: najmakori@ukm.edu.my

Cite this article: Periyasamy $\mathrm{P}$, et al. (2021). Aerosolized SARS-CoV-2 transmission risk: Surgical or N95 masks?. Infection Control \& Hospital Epidemiology, 42: 1150-1152, https://doi.org/10.1017/ice.2020.465 and droplet transmission. However, some have debated that it could be airborne. Airborne transmission occurs when particles of $<0.5 \mu \mathrm{m}$ within droplets spread through exhaled air via a process called aerosolization. These particles can remain in the air for long periods and can disseminate over distances $>1 \mathrm{~m}$. In the context of COVID-19, airborne particles can occur during certain aerosolgenerating procedures (AGPs). The World Health Organization (WHO) underlines the use of $\mathrm{N} 95$ respirators or equivalent as part 
of personal protective equipment (PPE) for healthcare workers (HCWs) managing COVID-19-positive patients when AGPs are being conducted.

This retrospective observational study describes the result of reverse-transcriptase polymerase chain reaction (RT-PCR) testing for severe acute respiratory coronavirus virus 2 (SARS-CoV-2) in HCWs wearing different form of PPE who had close contact with a confirmed COVID-19 patient during performing AGPs. All HCWs were quarantined for 14 days after the exposure. SARS-CoV-2 RT-PCR nasopharyngeal swabs were performed at different intervals. Little is known about the effectiveness of different types of PPE for preventing COVID-19 in HCWs. We describe the clinical outcome of HCWs exposed to sudden acute respiratory infection patient before the diagnosis of COVID-19 was known.

\section{Case report}

A 70-year-old man with known ischemic heart disease and dyslipidemia presented with severe headaches and cough for 1 week. He had a recent history of travelling to Russia in December 2019 and Jakarta in early February 2020. On presentation, no screening for SARS-CoV-2 was performed as Russia and Jakarta have not been flagged as epidemiological links to COVID-19 by the Malaysian Ministry of Health.

In the emergency department, he was tachypneic with respiratory rate of 28 breaths per minute, oxygen saturation of $86 \%$ in room air and requiring oxygen supplement of $40 \%$ via venturi mask. His condition worsened, requiring noninvasive mechanical ventilation (NIV); NIV failed and he was intubated. While awaiting transfer to the intensive care unit, manual ventilation via bagvalve-mask was performed. His chest radiography showed bilateral ground-glass opacities, mainly in the lower lobes.

In view of sudden acute respiratory infection, nasopharyngeal (NP) swabs were sent for SARS-CoV-2 real-time reverse-transcriptase polymerase chain reaction (RT-PCR) testing. Overall, $25 \mathrm{HCWs}$ were exposed to AGPs by this severe pneumonia patient who later tested positive for SARS-CoV-2. These procedures included nebulizer therapy, endotracheal intubation, invasive ventilation, and tracheal suctioning. The mean time of exposure was 34.4 minutes (range, 15-180 minutes). All 25 at-risk HCWs were placed on home quarantine for 14 days. They were monitored for cough, sore throat, headaches, myalgia and dyspnea. All HCWs with different levels of PPE and exposure times finally tested negative for SARS-CoV-2.

\section{Discussion}

COVID-19 is a very contagious disease that poses an occupational health risk to HCWs. SARS-CoV-2 transmission is believed to occur mainly through respiratory droplets. Current guidelines recommend the use of N95 masks and goggles during AGPs when attending to COVID-19 patients because the virus may become airborne under certain conditions. Respiratory PPE is particularly important to reduce the risk of respiratory infection in HCWs. A variety of PPE that provides different degrees of respiratory protection: medical face masks, respiratory protection equipment, goggles, and face shield. The size of the virus particle, the distance it can travel, and how deeply the virus can penetrate the host's respiratory tract are determinants of required PPE.

Medical masks have a fluid-resistant outer layer designed to prevent a stream of liquid entering the mouth. Medical masks are able to filter large particles but are not certified to protect users from airborne infections. Data concerning how well medical masks
Table 1. Types of the AGPs With the Type of PPE Used and Timing of COVID RT-PCR From Initial Exposure

\begin{tabular}{llllllc}
\hline & & \multicolumn{3}{c}{$\begin{array}{c}\text { No. of HCWs and Timing } \\
\text { of COVID-19 RT-PCR NP } \\
\text { Swab From Exposure }\end{array}$} \\
\cline { 2 - 7 } Type of AGP $(n=25)$ & PPE & Day 1 & Day 9 & Day 13 & Day 15 \\
\hline $\begin{array}{l}\text { Exposure to aerosol from } \\
\text { VM, nebulizer, or oral } \\
\text { suctioning }(n=15)\end{array}$ & $\begin{array}{l}\text { Surgical } \\
\text { mask }\end{array}$ & 15 & 15 & 13 & 15 \\
\cline { 2 - 7 } $\begin{array}{l}\text { Intubation }(n=3) \\
\text { N95 mask }\end{array}$ & 0 & 0 & 0 & 0 \\
\hline Ventilation $(n=7)$ & $\begin{array}{l}\text { Surgical } \\
\text { mask }\end{array}$ & 0 & 0 & 0 & 0 \\
\cline { 2 - 7 } & N95 mask & 3 & 0 & 3 & 0 \\
\hline & $\begin{array}{l}\text { Surgical } \\
\text { mask }\end{array}$ & 4 & 4 & 2 & 4 \\
\cline { 2 - 7 } & N95 mask & 3 & 0 & 3 & 0 \\
\hline
\end{tabular}

Note. AGP, aerosol-generating procedure; PPE, personal protective equipment; VM, ventimask; NP, nasopharyhgeal swab.

No. of HCWs and day of repeat NPO swab as above. All tested negative at each sampling.

work against SARS-CoV-2 are lacking. The N95 is a type of respirator able to filter out both large and small airborne particles. Factors that may affect the efficacy of N95 masks includes whether the HCW is trained in wearing N95 respirator and whether a fittest was conducted. In one study comparing fit-testing with no fittesting, there was no difference in respiratory infection risk between the 2 groups. ${ }^{1}$

The previous study claimed that there was insufficient evidence regarding the superiority of $\mathrm{N} 95$ masks over medical masks in protecting HCWs from transmissible acute respiratory infections in clinical settings. ${ }^{2}$ A study from Singapore reported on 41 HCWs exposed to an unknown COVID-19 patient during an AGP for $>10$ minutes, of whom $85 \%$ wore only surgical masks. All tested negative for SARS-CoV-2 by RT-PCR. ${ }^{3}$

A systematic review of 4 randomized controlled trials on masks showed that medical masks and N95 respirators offer similar protection against viral respiratory infection, including coronavirus, for HCWs during non-AGPs. ${ }^{4}$ The effectiveness of medical masks in protecting HCWs from SARS was inconsistent, and differing levels of exposure may explain such discrepancies. Xiao et $\mathrm{al}^{5}$ reported that masks did not prevent the transmission of influenza in 7 studies. On the contrary, Jefferson et $\mathrm{al}^{6}$ suggested that wearing masks significantly reduced the risk of SARS transmission.

Laboratory experiments have shown that SARS-COV-2 may remain viable for up to 3 hours, but clinical data have not demonstrated conclusively that SARS-CoV-2 is frequently spread via long distance airborne nuclei during routine care or following AGPs. ${ }^{7}$ All HCWs with different levels of PPE and exposure time tested negative for SARS-CoV-2. These findings are consistent with the meta-analysis, which showed the use of both N95 respirators and medical masks was associated with up to $80 \%$ reduction in risk of SARS. ${ }^{8}$ Other than the PPE that wore by our HCWs, we believe that the rate of clearance of aerosols may also affect the risk of infection in HCWs. Our general wards have around $\sim 6$ air exchanges per hour, which reduced air contaminants, assuming that a single air exchange eliminates $63 \%$ of airborne contaminants. ${ }^{9}$

In the case we presented, none of our HCWs wore N95 masks nor goggles. However, none of the 25 individuals at risk developed major symptoms, and serial NP swabs have proven that not one of them acquired the infection (Table 1). Our 
observation is therefore consistent with previous reports that have been unable to show that N95 masks were superior to 3ply masks in preventing transmission to HCWs performing AGPs. Further randomized control trial on ascertaining the effectiveness of the N95 respirators or medical masks in preventing HCWs from SARS-CoV-2 are warranted.

Acknowledgments. We thank the HCWs who consented to participate in the study.

Financial support. No financial support was provided relevant to this article.

Conflicts of interest. All authors report no conflicts of interest relevant to this article.

\section{References}

1. MacIntyre CR, Wang Q, Cauchemez S, et al. A cluster randomized clinical trial comparing fit-tested and non-fit-tested N95 respirators to medical masks to prevent respiratory virus infection in health care workers. Influenza Other Respir Virus 2011;5:170-179.

2. Smith JD, MacDougall CC, Johnstone J, Copes RA, Schwartz B, Garber GE. Effectiveness of N95 respirators versus surgical masks in protecting health care workers from acute respiratory infection: a systematic review and meta-analysis. CMAJ 2016;188:567-574.

3. Kangqi Ng, Beng Hoong Poon, et al. COVID-19 and the risk to health care workers: a case report. Ann Intern Med 2020;172:766-767.

4. Bartoszko JJ, Farooqi MAM, Alhazzani W, Loeb M. Medical masks vs N95 respirators for preventing COVID-19 in healthcare workers: a systematic review and meta-analysis of randomized trials. Influenza Other Respir Virus 2020;14:365-373.

5. Xiao J, Shiu EYC, Gao H, et al. Nonpharmaceutical measures for pandemic influenza in nonhealthcare settings-personal protective and environmental measures. Emerg Infect Dis 2020;26:967-975.

6. Jefferson T, Foxlee R, Del Mar C, et al. Physical interventions to interrupt or reduce the spread of respiratory viruses: systematic review. BMJ Clin Res 2008;336(7635):77-80.

7. Ong SWX, Tan YK, Chia PY, et al. Air, Surface environmental, and personal protective equipment contamination by severe acute respiratory syndrome coronavirus 2 (SARS-CoV-2) from a symptomatic patient. JAMA 2020;323:1610-1612.

8. Offeddu V, Yung CF, Low MSF, Tam CC. Effectiveness of masks and respirators against respiratory infections in healthcare workers: a systematic review and meta-analysis. Clin Infect Dis 2017;65:1934-1942.

9. Coia JE, Ritchie L, Adisesh A, et al. Guidance on the use of respiratory and facial protection equipment. J Hosp Infect 2013;85:170-182.

\title{
Sphingomonas paucimobilis infection among a patient with a history of injection drug use: An opportunity for improvement of medical chart documentation
}

\author{
Michael A. Goulart MPH, CIC, Marko Predic MS, CIC and Chad D. Neilsen MPH, CIC \\ Infection Prevention and Control, University of Florida Health Jacksonville, Jacksonville, Florida
}

To the Editor-At our level 1 academic trauma center in northeastern Florida, a patient developed a central-line-associated bloodstream infection (CLABSI) with Sphingomonas paucimobilis, an aerobic gram-negative bacillus that more commonly occurs in immunocompromised persons and is less commonly associated with nosocomial transmission. ${ }^{1-3}$ This patient was a female in her late twenties who was admitted for multifocal pneumonia after several days of cough and shortness of breath. Her medical history was remarkable for Hodgkin's lymphoma, chronic hepatitis $\mathrm{C}$ infection, thrombocytopenia, neutropenia, excoriation, tobacco use, and injection drug use (oxycodone). She denied current drug use. A double-lumen power peripherally inserted central catheter (PICC) was placed and dressed with a transparent dressing and chlorhexidine-gluconate impregnated antimicrobial disc (BioPatch) according to hospital policy. Approximately 1 month into her stay, blood cultures were positive for S. paucimobilis. Medical staff had documented patient noncompliance with hospital polices, such as dressing changes, on multiple occasions. After a 57-day stay, the patient was discharged to home hospice.

\footnotetext{
Author for correspondence: Michael Goulart, E-mail: michael.goulart@jax.ufl.edu Cite this article: Goulart MA, Predic M, and Neilsen CD. (2021). Sphingomonas paucimobilis infection among a patient with a history of injection drug use: An opportunity for improvement of medical chart documentation. Infection Control \& Hospital Epidemiology, 42: 1152-1153, https://doi.org/10.1017/ice.2020.430
}

Whether the patient acquired S. paucimobilis due to her immunocompromised state and/or noncompliance with hospital policies is unknown. There was a paucity of information regarding her past history of injection drug use, as documented by clinical staff during her admission. Current injection drug use may have contributed to the development of the CLABSI. Walayat et $\mathrm{al}^{4}$ noted the isolation of $S$. paucimobilis in an injection drug user, which presented itself as acute phlebitis; these authors suspected the patient acquired the organism from using toilet water to mix heroin prior to injecting. ${ }^{4}$ We urge clinicians to thoroughly document past drug use, especially among past and current injection drug users, to note when suspected drug use has occurred, and/or to note suspicion if a patient has accessed their own vascular catheter. This is critical in wake of the ongoing opioid epidemic linked to injection drug use, which has affected many states across the United States, including Florida, which has also been facing an ongoing outbreak of the hepatitis A virus. Since January 2018, more than one-third of reported cases in the state have reported injection drug use. ${ }^{5}$ According to the Centers for Disease Control and Prevention (CDC) National Healthcare Safety Network definitions, even if a patient accesses their own vascular catheter during their hospital stay, whether through injection drug use or other means, and it meets the CLABSI case definition, it is still attributed to the reporting facility. ${ }^{6}$ The CDC recommend that risk mitigation include a sitter for the patient and/or removing the tunneled catheter as soon as clinically 